\title{
The Synthesis and Some Properties of Nylon 4,T
}

\author{
R. J. GAYMANS, Twente University of Technology, Polymer Laboratory \\ P.O. Box 217, 7500 AE Enschede, The Netherlands
}

\section{Synopsis}

The synthesis of nylon 4,T from tetramethylenediamine and a terephthalic acid derivative was studied in a two step-process: prepolymerization, followed by postcondensation in the solid state $\left(4 \mathrm{~h}, 290^{\circ} \mathrm{C}\right)$. The prepolymers were prepared by the nylon salt method, ester polymerization method, interfacial method, and a low temperature solution method. $\mathbf{A}$ maximum $\eta_{\text {inh }}$ of 1.52 was obtained. From a solution in trifluoroacetic acid, films were cast and on these films we studied its IR spectrum, WAXS, and melting behavior with DSC. A boiled up sample had a double melting transition at 434 and $475^{\circ} \mathrm{C}$ and a $\Delta H_{f}$ of $130 \mathrm{~J} / \mathrm{g}$.

\section{INTRODUCTION}

Partial aromatic polyamides have a high glass transition temperature and a strong chain interaction., ${ }^{1,2}$ If this partial aromaticity is combined with a regular spacing of the amide groups in the chain, their crystallinities are also high. Fiber properties of these polymers are characterized as having a high initial modulus, good strength, and good high temperature properties. ${ }^{2,3}$ However, with this high order the melting temperatures are highmostly too high for melt processing - and fibers have to be spun by a sqlution method.

One of these partial aromatic polyamides with a high amide content and a regular amide spacing is polytetramethyleneterephthalamide (nylon 4,T).

This polymer can be prepared from tetramethylenediamine and a terephthalic acid derivative. Nylon 4,T has a similar amide spacing as nylon 4,6 and poly-p-phenyleneterephthalamide. The synthesis of this polymer has been studied by an interfacial and a low-temperature solution method.

Shashoua and Eareckson ${ }^{2}$ prepared the material by an interfacial method from terephthaloyl chloride (TCl) in methylene chloride $(0.015 \mathrm{~mol} / \mathrm{L})$ and tetramethylenediamine (TMDA) $(0.015 \mathrm{~mol} / \mathrm{L})$ with potassium hydroxide $(0.030 \mathrm{~mol} / \mathrm{L})$ in water. The so obtained polymer had an $\eta_{\text {inh }}$ of 1.20 . In a Celanese patent ${ }^{4}$ the nylon 4,T syntheses has been described with $\mathrm{TCl}$ in xylene $(0.1 \mathrm{~mol} / \mathrm{L})$ and TMDA $(0.1 \mathrm{~mol} / \mathrm{L}), \mathrm{MgO}$ in water; their reported $\eta_{\text {inh }}$ was 1.56 .

Aubineau et al. ${ }^{5}$ studied the syntheses in solution. To a solution of TMDA $(0.1 \mathrm{~mol} / \mathrm{L})$ and triethylamine $(0.2 \mathrm{~mol} / \mathrm{L})$ in chloroform TCl $(0.1 \mathrm{~mol} / \mathrm{L})$ was added. The precipitated polymer had an $\eta_{\text {inh }}$ of 0.58 .

As yet, no high temperature synthesis has been reported. At higher temperatures side reactions may take place such as the cyclization of TMDA to pyrrolidine, a cyclic monofunctional secondary amine. Nylon $4, \mathrm{~T}$ has a high crystallinity and a melting point as measured with DTA of $436^{\circ} \mathrm{C} .{ }^{2}$ The polymer is very insoluble and only sulfuric acid and trifluoroacetic acid are given as solvents. ${ }^{2}$ Fibers could be spun from $\mathrm{H}_{2} \mathrm{SO}_{4}$ solutions and 
they had a high initial modulus of $90 \mathrm{~g} / \mathrm{den}$ combined with a good strength of $5.5 \mathrm{~g} / \mathrm{den}$. We had another look at the synthesis of this polymer and studied some of its properties.

\section{EXPERIMENTAL}

\section{Materials}

The materials terephthaloyl chloride ( $\mathrm{TCl}$ ), tetramethylenediamine (TMDA), hexamethylenephosphourostriamide (HMPT), $n$-methylpyrrolidon (NMP), and tetrahydrofuran (THF) and chloroform were distilled prior to their use. All other chemicals were used as received.

\section{Polymerization}

Nylon 4,T salt: To a solution of $106 \mathrm{~g}$ TMDA $(1.2 \mathrm{~mol})$ in $1000 \mathrm{~mL}$ of water was added $200 \mathrm{~g}$ terephthalic acid (TA) $(1.2 \mathrm{~mol})$. The temperature increased to $60^{\circ} \mathrm{C}$ and at some point the solution was virtually clear. After cooling the mass was precipitated by adding $2 \mathrm{~L}$ of ethanol. The salt was filtered, washed, and dried ( $287 \mathrm{~g})$. A $1 \%$ solution in water had a $\mathrm{pH}$ of 7.25 .

Salt polymerization: Ten grams of nylon salt and $3 \mathrm{~g}$ solvent were charged in a $100 \mathrm{~mL}$ stainless steel autoclave. After flushing with nitrogen, a starting pressure of 5 bar was given. The autoclave warmed up in 60 min to $210^{\circ} \mathrm{C}$ and remained at that temperature for $2 \mathrm{~h}$.

Ester polymerization: Ten grams of Dimethylterephthalate (DMT) $(0.051 \mathrm{~mol})$ and $4.54 \mathrm{~g}$ TMDA $(0.051 \mathrm{~mol})$ were charged in a $100 \mathrm{~mL}$ stainless steel autoclave. After flushing with nitrogen a starting pressure of 5 bar was given. The autoclave warmed up in $60 \mathrm{~min}$ to $215^{\circ} \mathrm{C}$ and remained at that temperature for $2 \mathrm{~h}$. The reaction mass was stirred with a magnetic stirrer.

Interfacial polymerization: To TMDA $(0.01 \mathrm{~mol})$ and $\mathrm{KOH}(0.02 \mathrm{~mol})$ in $100 \mathrm{~mL}$ of water was added under vigorously stirring TCl $(0.01 \mathrm{~mol})$ in $100 \mathrm{~mL}$ of methylene chloride. The precipitated polymer was filtered, washed, and dried.

Solution polymerization: To TCl $(0.015 \mathrm{~mol})$ in $100 \mathrm{~mL}$ of THF cooled to $-15^{\circ} \mathrm{C}$ was added TMDA $(0.015 \mathrm{~mol})$ and diisopropylethylamine $(0.030$ mol) in $20 \mathrm{~mL}$ of THF. The formed precipitate was filtered and washed with boiling water.

Solid state postcondensation: Three-gram samples of a prepolymer were postcondensed in the solid state in a fluidized bed reactor ${ }^{6}$ in a stream of dry nitrogen.

\section{Characterization}

Inherent viscosities $\left(\eta_{\text {inh }}\right)$ were determined from $0.5 \%$ solutions in $96 \%$ sulfuric acid at $25^{\circ} \mathrm{C}$. Films were cast from trifluoroacetic acid solutions. The melting behavior was studied with a duPont 990 Thermal Analyser DSC unit at a heating rate of $10^{\circ} \mathrm{C} / \mathrm{min}$. The peak temperatures were taken 
as the melting points. For wide angle x-ray analysis (WAXS) a Kiessig pinhole vacuum camera was used.

\section{RESULTS AND DISCUSSION}

\section{Synthesis}

We studied the polymerization or prepolymerization of nylon $4, T$ with:

-the nylon 4,T salt, in an autoclave

-DMT-TMDA mixtures, in an autoclave

- TCl and TMDA, and a stirred interfacial method

- TCl and TMDA, and a solution method and on some samples a postcondensation in the solid state was conducted.

\section{Nylon Salt}

The prepolymerization of the nylon 4,T salt in an autoclave was studied at $210^{\circ} \mathrm{C}$. This temperature was chosen because at higher prepolymerization temperatures cyclization of TMDA to pyrrolidine might take place. As this salt has a high melting temperature $\left(286^{\circ} \mathrm{C}\right)$ and because prepolymerization in the liquid state is preferred, the effect of presence of solvent was studied. The results of these reactions are given in Table $\mathrm{I}$.

In the experiment without a solvent the salt had not melted, but some polymerization had taken place. By the polymerizations in the presence of $30 \%$ solvent the salt had "melted" but the viscosities of products were low too. That only very low molecular weight prepolymers were obtained must be due to the low reactivity of the aromatic acid.?

\section{DMT-TMDA Mixture}

The polymerization with equimolar mixture of DMT and TMDA was studied without a solvent in an autoclave for $2 \mathrm{~h}$ at $215^{\circ} \mathrm{C}$. The prepolymer had an $\eta_{\text {inh }}$ of 0,10 which is only marginally higher than the viscosities of the prepolymers obtained by the nylon salt method.

\section{Interfacial Polymerization}

The polymerization was studied with TCl-solvent/TMDA-KOH-water system. The effect of varying the solvent is given in Table II. The viscosity

TABLE I

Nylon Salt Polymerization in an Autoclave for $2 \mathrm{~h}$ at $210^{\circ} \mathrm{C}$

\begin{tabular}{ll}
\hline \multicolumn{1}{c}{ Solvent } & $\eta_{\text {inh }}$ \\
\hline NO solvent & 0.08 \\
$30 \%$ water & 0.09 \\
$30 \%$ m-cresol & 0.09 \\
$30 \%$-hydroxybiphenyl & 0.09 \\
$30 \%$ glycol & 0.08 \\
\hline
\end{tabular}


TABLE II

Interfacial Polymerization at $0.1 \mathrm{~mol} / \mathrm{L}$

\begin{tabular}{lcc}
\hline $\begin{array}{c}\text { Solvent for terephthaloyl } \\
\text { chloride }\end{array}$ & Acid acceptor & $\eta_{\text {inh }}$ \\
\hline Toluene & KOH & 0.45 \\
Methylene chloride & KOH & 0.55 \\
Chloroform & KOH & 0.51 \\
$o$-Xylene & MgO & 0.45 \\
\hline
\end{tabular}

of the polymer prepared with methylene chloride was somewhat higher than with chloroform or toluene and also higher than with xylene and $\mathrm{MgO}$.

The effect of concentration was studied with methylene chloride (Fig. 1). As can be seen with decreasing concentration of the reactants the viscosities of the products increased. The extrapolated viscosities at extremely low concentrations are comparable to the results of Shashoua and Eareckson. ${ }^{1}$

\section{Solution Polymerization}

The low temperature solution polymerization starting from TCL and TMDA was studied with varying the solvent system and the acid binder (Table III). With the solvents HMPT and NMP, the polymer precipitated after 5 min reacting; with THF, the polymer precipitated immediately. The polymers prepared in THF, however, had a higher molecular weight. More important than the type of solvent, seems to be the acid binder. The aliphatic diamines are strongly basic therefore only very strong tertiary amines are effective acid binders. The viscosities remained low with HMPT, TMDA, or TEA.

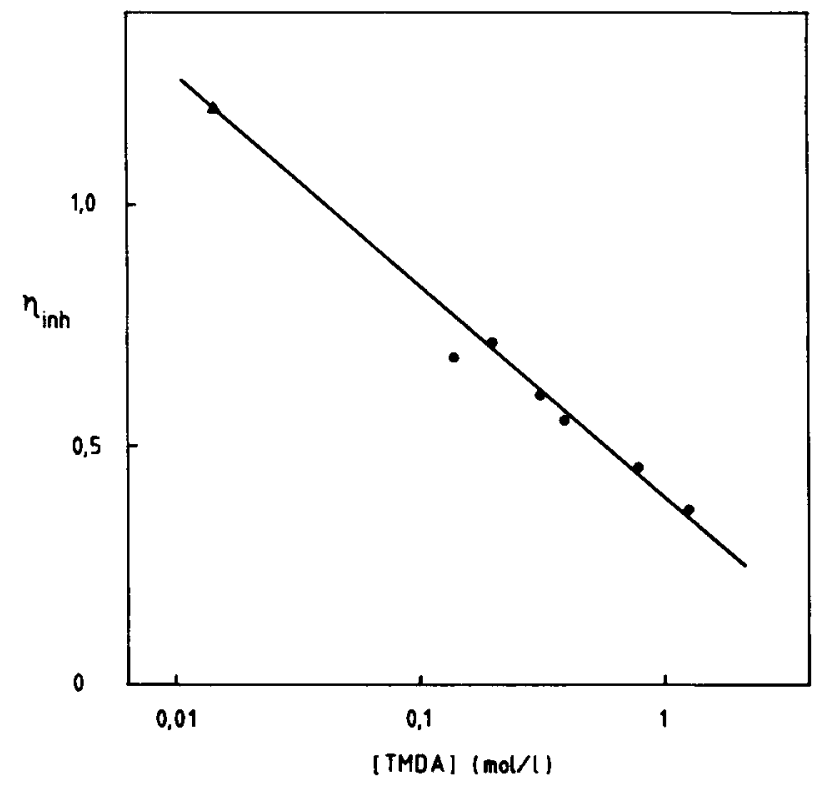

Fig. 1. Influence of TMDA concentration by the interfacial polymerization with the system $\mathrm{TCl}$, methylenechloride and TMDA, KOH in water. $(\mathbf{\Lambda})$ from Shashoua and Eareckson. ${ }^{1}$ 
TABLE III

Low Temperature Solution Polymerization Influence of Solvent and Acid Binder

\begin{tabular}{lccccc}
\hline Solvent & $\begin{array}{c}\text { Concentration } \\
(\mathrm{mol} / \mathrm{L})\end{array}$ & $\begin{array}{c}\text { Acid-amine } \\
\text { ratio }\end{array}$ & $\begin{array}{c}\text { Acid } \\
\text { binder }\end{array}$ & $\eta_{\text {inh }}$ & \multicolumn{1}{c}{ Remarks } \\
\hline HMPT & 0.1 & $1: 1$ & - & 0.10 & Slow precipitation \\
HMPT & 0.1 & $1: 2$ & TMDA $^{\mathrm{a}}$ & 0.10 & Slow precipitation \\
HMPT & 0.1 & $1: 1$ & TEA $^{\mathrm{b}}$ & 0.08 & Slow precipitation \\
NMP & 0.15 & $1: 1$ & DMBA $^{\mathrm{c}}$ & 0.31 & Slow precipitation \\
THF & 0.15 & $1: 1$ & DMBA $^{\mathrm{c}}$ & 0.34 & Fast precipitation \\
THF & 0.15 & $1: 1$ & DIPEA $^{\mathrm{d}}$ & 0.39 & Fast precipitation \\
\hline
\end{tabular}

a TMDA = tetramethylenediamine.

- TEA = triethylamine.

'DMBA = dimethylbenzylamine.

${ }^{\mathrm{d}}$ DIPEA $=$ diisopropylethylamine.

Higher viscosities could be obtained with $N, N^{\prime}$-dimethylbenzylamine (DMBA) and $N, N^{\prime}$-diisopropylethylamine (DIPEA).

\section{Postcondensation in the Solid State}

An effective way of increasing the molecular weight of a condensation polymer with a high melting temperature is postcondensation in the solid state. ${ }^{6}$ For nylon $4, T$ with a melting temperature of over $400^{\circ} \mathrm{C}^{1}$ low solubility, and low reactivity, this polymerization method seemed suitable. We studied the solid-state postcondensation with a fluidized bed reactor $(4 \mathrm{~h}$, $290^{\circ} \mathrm{C}$ ). The starting materials were prepolymers which preparation we have described earlier and the results are given in Table IV.

The prepolymer prepared by the low temperature solution method could be postcondensed to a high molecular weight. Of the other three prepolymers their viscosities increased only a little, possibly due to an imbalance of the reactive end groups.

\section{PROPERTIES}

\section{Solubility}

The solubility of nylon 4,T is known to be low. ${ }^{1}$ The polymer is insoluble in benzyl alcohol, phenol, formic acid, or NMP-LiCl. It is soluble in very

TABLE IV

Postcondensation of Some Prepolymers in the Solid State for $4 \mathrm{~h}$ at $290^{\circ} \mathrm{C}$

\begin{tabular}{llcc}
\hline \multicolumn{1}{c}{ Prepolymerization } & & $\begin{array}{c}\text { Postcondensation } \\
\left(4 \mathrm{~h}, 290^{\circ} \mathrm{C}\right)\end{array}$ \\
\hline \multicolumn{1}{c}{ Method } & \multicolumn{1}{c}{ Conditions } & $\eta_{\text {inh }}$ & 0.19 \\
Nylon salt & No solvent, $2 \mathrm{~h}, 210^{\circ} \mathrm{C}$ & 0.08 & 0.23 \\
Ester & $2 \mathrm{~h}, 215^{\circ} \mathrm{C}$ & 0.10 & 0.70 \\
Interfacial & Methylene chloride, $\mathrm{KOH}_{\text {Solution }}$ & 0.62 & 1.09 \\
Solution & THF, DMBA & 0.34 & 1.52 \\
\hline
\end{tabular}

aMBA = dimethylbenzylamine.

${ }^{b}$ DIPEA $=$ diisopropylethylamine. 
strong acids such as con. sulfuric acid, trifluoroacetic acid (TFA), and dichloroacetic acid.

\section{Film Formation}

Films up to $0.1 \mathrm{~mm}$ thick were formed from $5 \%$ solutions in trifluoroacetic acid. From solutions in $\mathrm{H}_{2} \mathrm{SO}_{4}$ films could be cast by precipitating in water, but these films had a high void content.

\section{Infrared Analyses}

The infrared spectrum of a polymer film (form TFA sol.) was recorded and in Table $\mathrm{V}$ the assignments of these bands are given. Crystalline bands are at 1160 and $730 \mathrm{~cm}^{-1}$ and an amorphous band at $1200 \mathrm{~cm}^{-1}$.

\section{X-Ray Analyses}

The wide angle $x$-ray analyses of a film sample gave two sharp rings at 3.87 and $4.87 \AA$. These are both larger than the $d_{010}$ and $d_{100}$ of nylon 4,6 (3.71 and 4.30$)^{8}$ and $6,6(3.73 \text { and } 4.34)^{9}$

\section{DSC}

No second-order transition was observed with DSC. The melting transition had two endothermic peaks. A double melting transition is for polymers quite common and has been explained as a melting-recrystallization-melting effect ${ }^{10}$ and the temperature of the first endotherm is sensitive to the thermal history of the sample. The effect of thermal history was studied and the transition temperatures and the heats of melting are given in Table VI. After a crystallization treatment the first transition $\left(T_{\mathrm{I}}\right)$ rises from 427

TABLE V

Infrared Spectrum

\begin{tabular}{|c|c|c|}
\hline $\begin{array}{l}\text { Wave number } \\
\qquad\left(\mathrm{cm}^{-1}\right)\end{array}$ & Intensity & Assignments \\
\hline 3310 & vs & $\nu(\mathrm{N}-\mathrm{H})$ \\
\hline 3070 & $\mathbf{m}$ & $2 \times$ amide II \\
\hline 2940 & $\mathbf{m}$ & $\nu_{\alpha}\left(\mathrm{CH}_{2}\right)$ \\
\hline 2870 & $\mathbf{w}$ & $\nu_{n}\left(\mathrm{CH}_{2}\right)$ \\
\hline 1625 & vs & Amide $\mathrm{I},(\mathrm{C}=\mathrm{O})$ \\
\hline 1540 & vs & Amide II, $\delta \mathrm{CHN}$ ) \\
\hline 1490 & $\mathbf{s}$ & $\nu(\mathbf{C}=\mathrm{C})$ arom. \\
\hline 1440 & vw & $\delta_{8}\left(\mathrm{CH}_{2}\right)$ \\
\hline 1370 & vw & $\gamma_{w}\left(\mathrm{CH}_{2}\right)$ \\
\hline 1315 & $\mathbf{s}$ & $\gamma_{w}\left(\mathrm{CH}_{2}\right)$ \\
\hline 1290 & $\mathbf{s}$ & Amide III? \\
\hline 1240 & $\mathbf{w}$ & $\gamma_{t}\left(\mathrm{CH}_{2}\right)$ \\
\hline 1195 & $\mathbf{m}$ & $v(a-c)$ \\
\hline 1155 & $\mathbf{m}$ & \\
\hline 1110 & $\mathbf{m}$ & $\delta_{i}(\mathrm{CH})$ arom. \\
\hline 1015 & $\mathbf{m}$ & $\delta_{i}(\mathrm{CH})$ arom. \\
\hline 800 & $\mathbf{s}$ & $\pi$-band \\
\hline 730 & $\mathrm{~m}$ & Amide IV \\
\hline 650 & s-broad & Amide V \\
\hline
\end{tabular}


TABLE VI

DSC Analysis of Films

\begin{tabular}{lccc}
\hline & $\begin{array}{c}T_{\mathrm{I}} \\
\left({ }^{\circ} \mathrm{C}\right)\end{array}$ & $\begin{array}{c}T_{\mathrm{II}} \\
\left({ }^{\circ} \mathrm{C}\right)\end{array}$ & $\begin{array}{c}\Delta H_{m} \\
(\mathrm{~J} / \mathrm{g})\end{array}$ \\
\hline Film & & & \\
As cast (TFA) & 427 & 475 & 108 \\
$1 \mathrm{~h}, 100^{\circ} \mathrm{C}, \mathrm{H}_{2} \mathrm{O}$ & 434 & 475 & 129 \\
$1 \mathrm{~h}, 166^{\circ} \mathrm{C}, \mathrm{DMAC}$ & 434 & 475 & 167 \\
$1 \mathrm{~h}, 20^{\circ} \mathrm{C}, 42 \% \mathrm{H}_{2} \mathrm{SO}_{4}$ & 432 & 475 & 140 \\
$10 \mathrm{~min}, 300^{\circ} \mathrm{C}$ in press & 435 & 475 & 163 \\
\hline
\end{tabular}

to $435^{\circ} \mathrm{C}$. The second endotherm $\left(T_{\mathrm{II}}\right)$ is at $475^{\circ} \mathrm{C}$. This is $40-50^{\circ} \mathrm{C}$ higher than the first transition.

The heats of melting $\left(\Delta H_{m}\right)$ rises with crystallization treatment too. With the data of Van Krevelen ${ }^{11}$ an estimate of the heat of melting of a $100 \%$ crystalline material was calculated to be $200 \mathrm{~J} / \mathrm{g}$. With this figure the degree of crystallinity, $x_{c}$, were found to be $50-80 \%$-which is high.

\section{CONCLUSIONS}

The synthesis of nylon 4,T to a high molecular weight can either be accomplished by interfacial polymerization at very low concentrations 0.015 $\mathrm{mol} / \mathrm{L}\left(\eta_{\text {inh }} 1.20\right),{ }^{1}$ or a two-step process whereby first a prepolymer is made by a low temperature solution reaction followed by a postcondensation in the solid state at high temperatures $\left(\eta_{\text {inh }} 1.52\right)$. Nylon $4, T$ has a high amide content and a regular spacing of the amide groups. The polymer is highly crystalline and has a high melting transition. A new look at its film and fiber properties would be of interest.

The author wishes to thank Jr. A. Beekhof for his contribution and Prof. Jr. J. Schuijer for his active interest.

\section{References}

1. V. E. Shashoua and W. M. Eareckson, J. Polym. Sci., 15, 343 (1959).

2. P. W. Morgan and S. L. Kwolek, Macromolecules, 8, 104 (1975).

3. B. S. Spraque and R. W. Singleton, Tex. Res. J., 35, 999 (1965).

4. French Pat. 1,300,756 (to Celanese Corp. of America) (25 February 1961).

5. C. Aubineau, R. Audebert, and G. Champentier, Bull. Soc. Chim. France, 533 (1970) and 1404 (1970).

6. R. J. Gaymans, J. Amirtharaj, and H. Kamp, J. Appl. Polym. Sci., 27, 2513 (1982).

7. R. D. Chapman, D. A. Holmer, O. A. Pickett, K. R. Lea, and J. H. Saunders, Tex. Res. J., 51, 564 (1981).

8. R. J. Gaymans, T. E. C. van Utteren, J. W. A. van den Berg, and J. Schuijer, J. Polym. Sci. Polym. Chem. Ed., 15, 537 (1977).

9. J. Masamoto, K. Sasaguri, C. Ohizumi, and H. Kobayashi, J. Polym. Sci. Polym. Phys. Ed., 8, 1703 (1970).

10. B. Wunderlich, Polymer Physics, Vol. 3, Academic, New York, 1980, Chap. 8.3.

11. D. W. van Krevelen, Properties of Polymers, Elsevier, Amsterdam, 1976, Chap. 5.

Received July 27, 1984

Accepted October 25, 1984 